\title{
SUMMARY OF SCAN SITE 10
}

\author{
S. M. Smith, D. A. Johnson and G. Shor \\ Scripps Institution of Oceanography, La Jolla, California
}

\section{SURVEY AREA}

\section{General Information}

The extent of the surveyed area is approximately 30 by 40 miles, bounded by latitudes $13^{\circ} 50^{\prime} \mathrm{N}$ and $14^{\circ} 20^{\prime} \mathrm{N}$, and longitudes $140^{\circ} 00^{\prime} \mathrm{W}$ and $140^{\circ} 45^{\prime} \mathrm{W}$. The survey of this site was made from the Argo between April 2023,1969 . Weather conditions at the time of survey (22 April, 0600) were: ENE winds of 14 knots, moderate seas (ENE) with swells of 5 feet, and cloudy skies. The barometric pressure was 29.94 ; and, sea and air temperatures were $74^{\circ} \mathrm{F}$ and $76^{\circ} \mathrm{F}$, respectively. An estimated drift of one knot set to west was found consistently throughout the survey.

\section{Bathymetry}

With a regional depth of 4755 meters, the survey area is characterized by a series of abyssal hills. Groups of several hills, each 37 to 55 meters high, are separated by troughs 91 to 183 meters deep. These troughs are very narrow and $\mathrm{V}$-shaped, not flat-floored. The troughs and groups of hills are strongly lineated in a northsouth direction.

\section{Structure and Magnetics}

A strong subbottom reflector is present, and is generally conformable with the overlying sea floor. Overlying this reflector is a relatively transparent sediment layer with thickness ranging from 0.10 to 0.15 second. An additional 0.10 second of sediment appears to be present beneath the transparent layer. The sediment is uniformly distributed over surveyed area, with no evidence of "ponding".
Amplitude of surface anomalies is 50 to 100 , with a wave length of 20 to 30 miles in an east-west direction. The magnetic anomalies are strongly lineated along a direction of $350^{\circ}$

\section{DESCRIPTION OF SITE 10}

Site 10 is located at latitude $13^{\circ} 52.1^{\prime} \mathrm{N}$, longitude $140^{\circ} 10.3^{\prime} \mathrm{W}$ (see profile EF), in a region of relatively low abyssal hills, midway between two troughs which are 5 miles apart. The thickness of the transparent layer is about 0.10 second.

\section{NATURE OF SITE}

\section{SCAN-10-P}

Core length: 8.6 meters. This core recovered 300 centimeters of siliceous ooze overlying a white calcareous ooze.

\section{SCAN-11-P}

Core length: 10.83 meters. Located west of Site 9, this core sampled a dark brown siliceous ooze, overlying a lighter brown calcareous-siliceous ooze.

\section{SCAN-12-P}

Core length: 7.6 meters. This core, recovered from the west flank of the trough cored at SCAN-11-P, detected strong reflectors occurring several meters beneath the sea floor. Sediment sampled here is a siliceous ooze overlying a calcareous ooze.

The camera lowering at Site 10 identified scattered manganese nodules (to 10 centimeters in diameter), a few small mounds of sediment, and current ripples. The heat flow measured was $2.20 \mu \mathrm{cal} / \mathrm{cm}^{2} \mathrm{sec}$. 


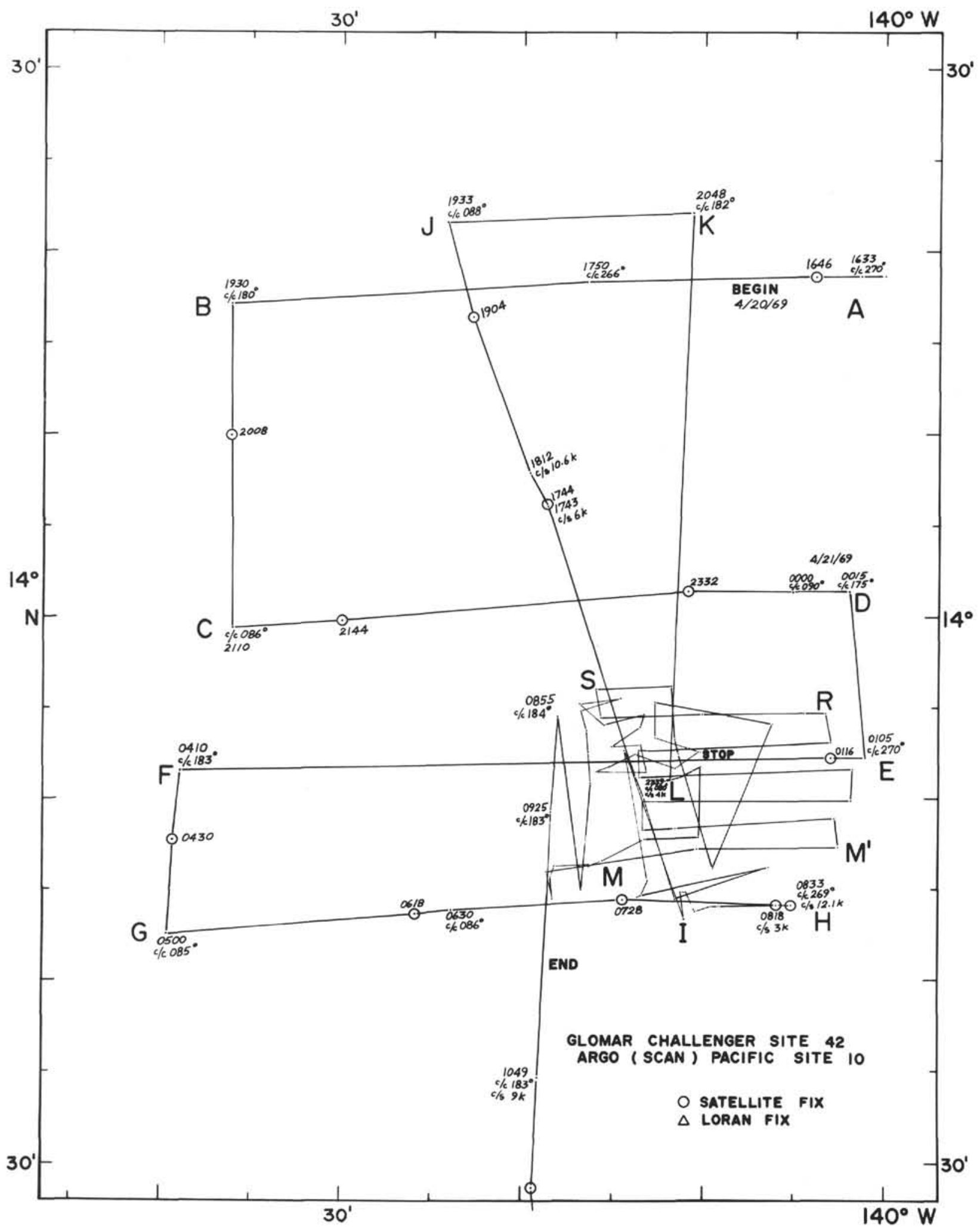




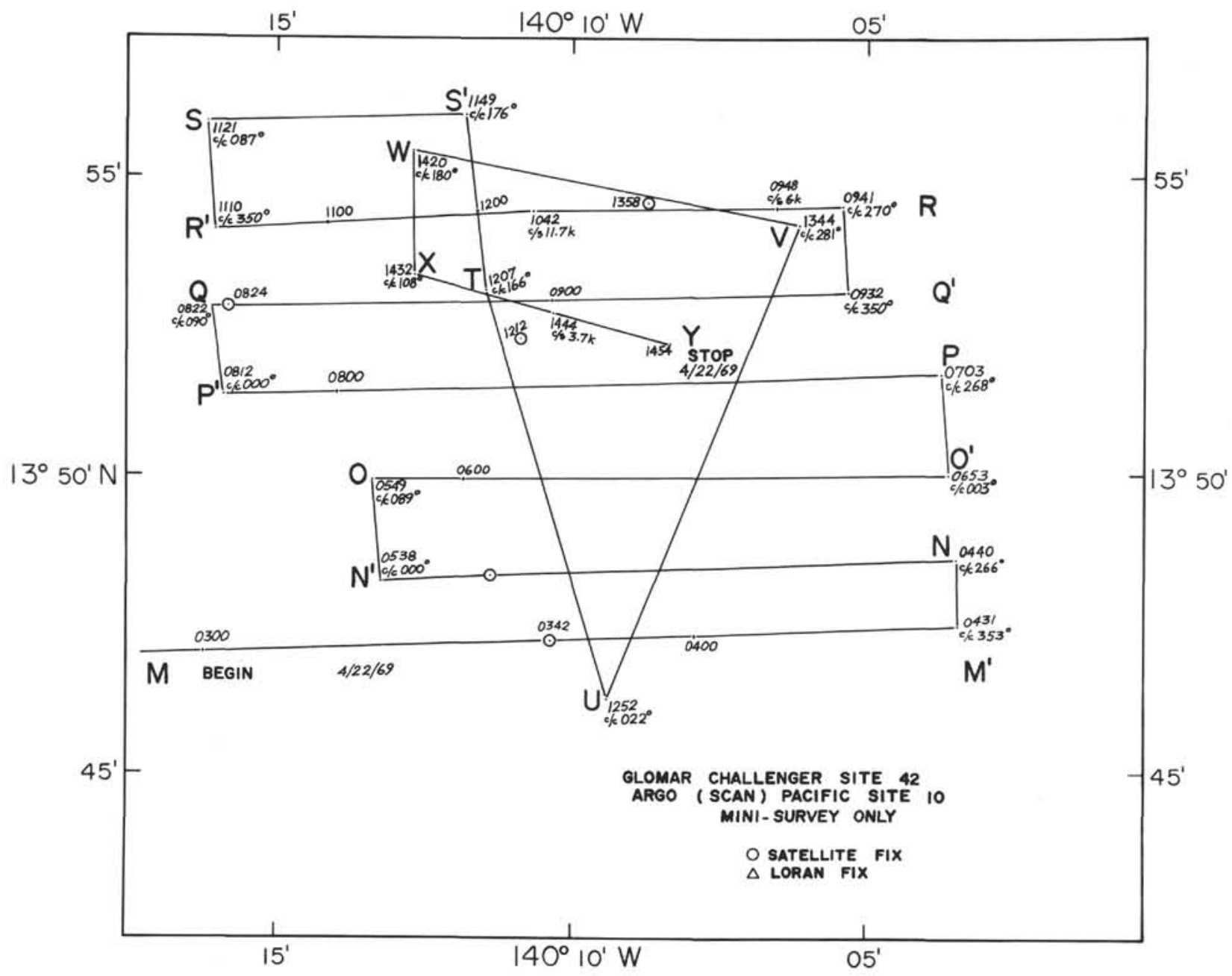



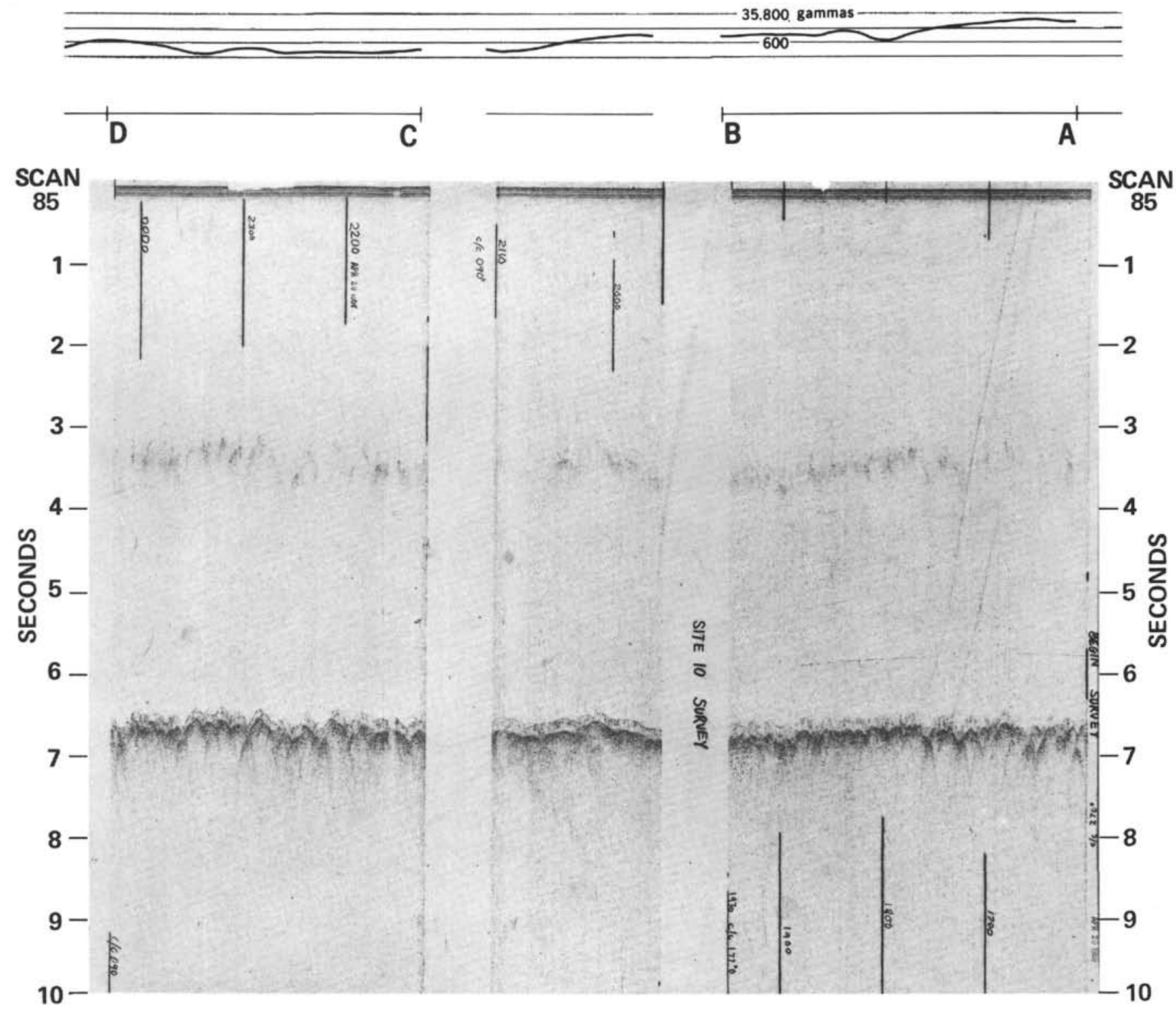

SCAN Survey, Site 10, Tracks A, B, C and D. 


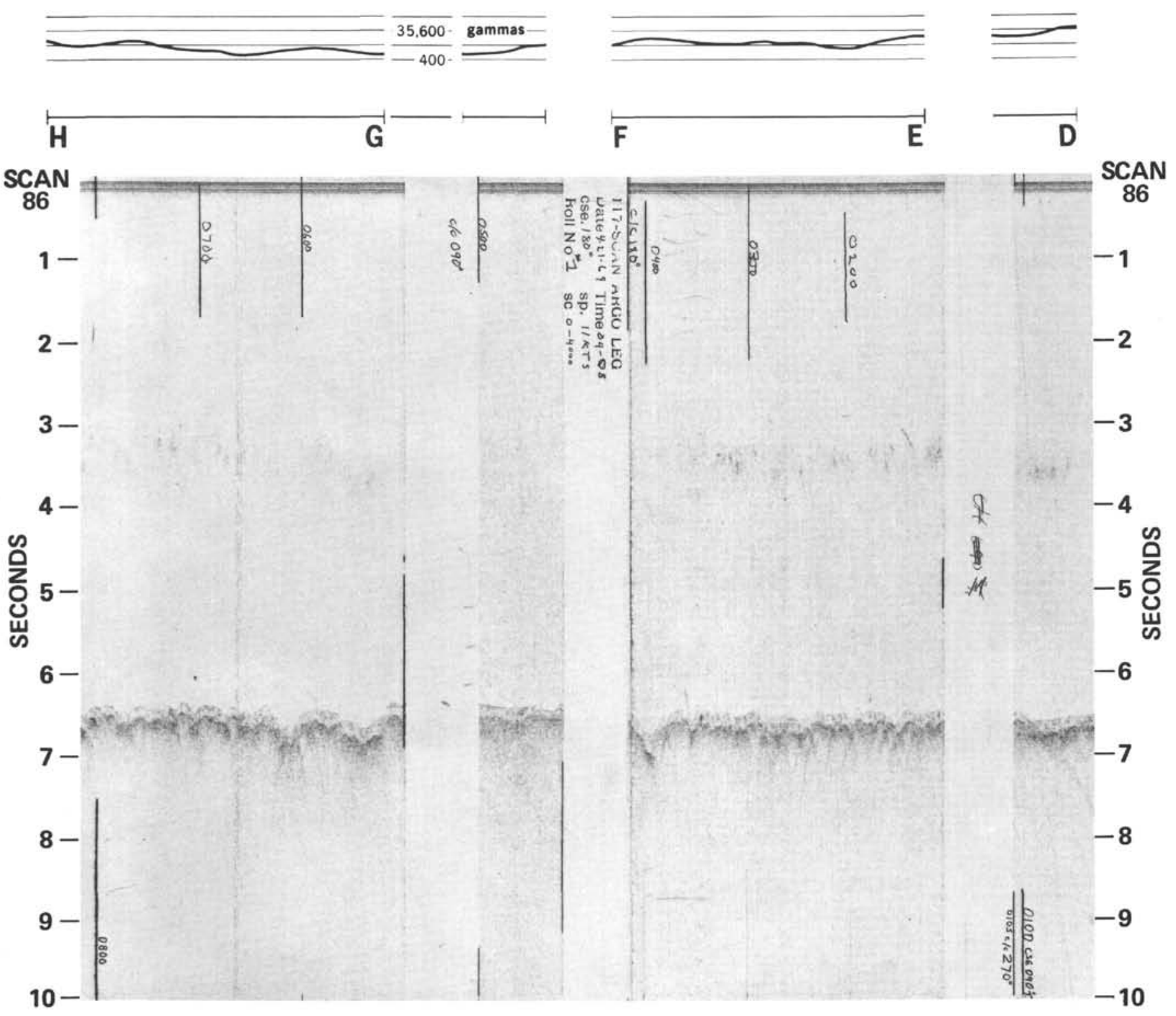

SCAN Survey, Site 10, Tracks $D, E, F, G$ and $H$. 


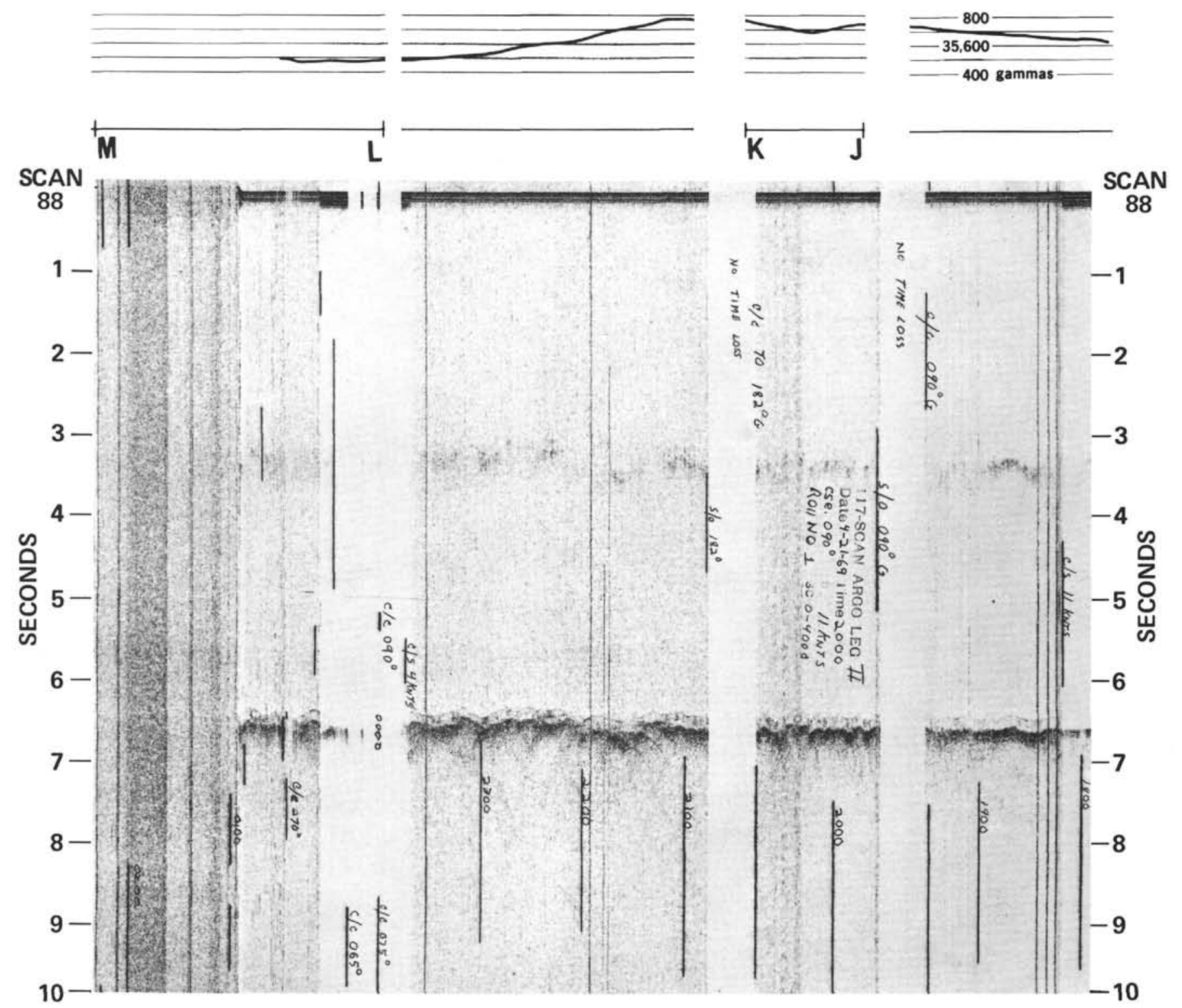

SCAN Survey, Site 10, Tracks $J, K, L$ and $M$. 


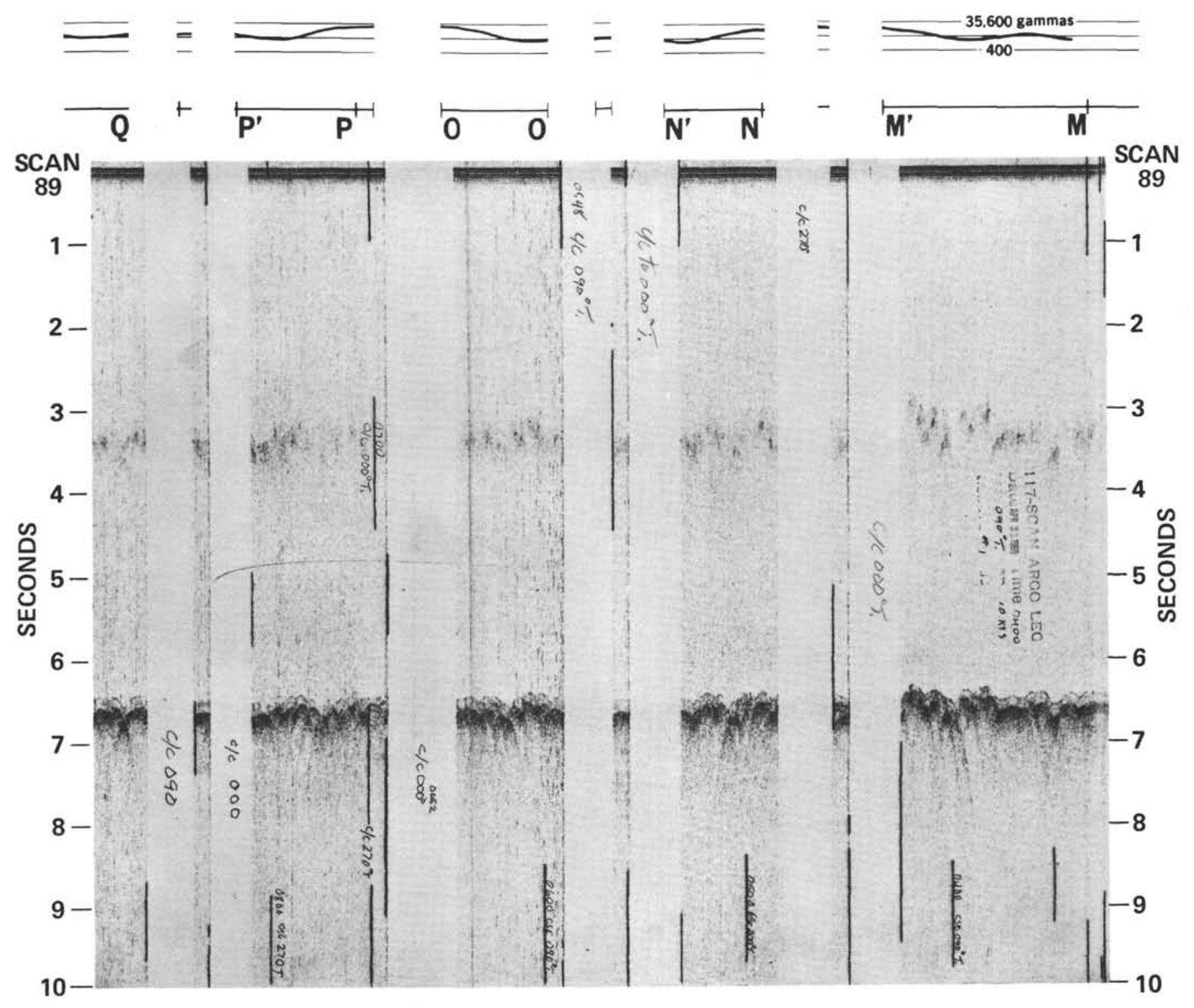

SCAN Survey, Site 10 , Tracks $M, M^{\prime}, N, N^{\prime}, O, O^{\prime}, P, P^{\prime}$ and $Q$. 


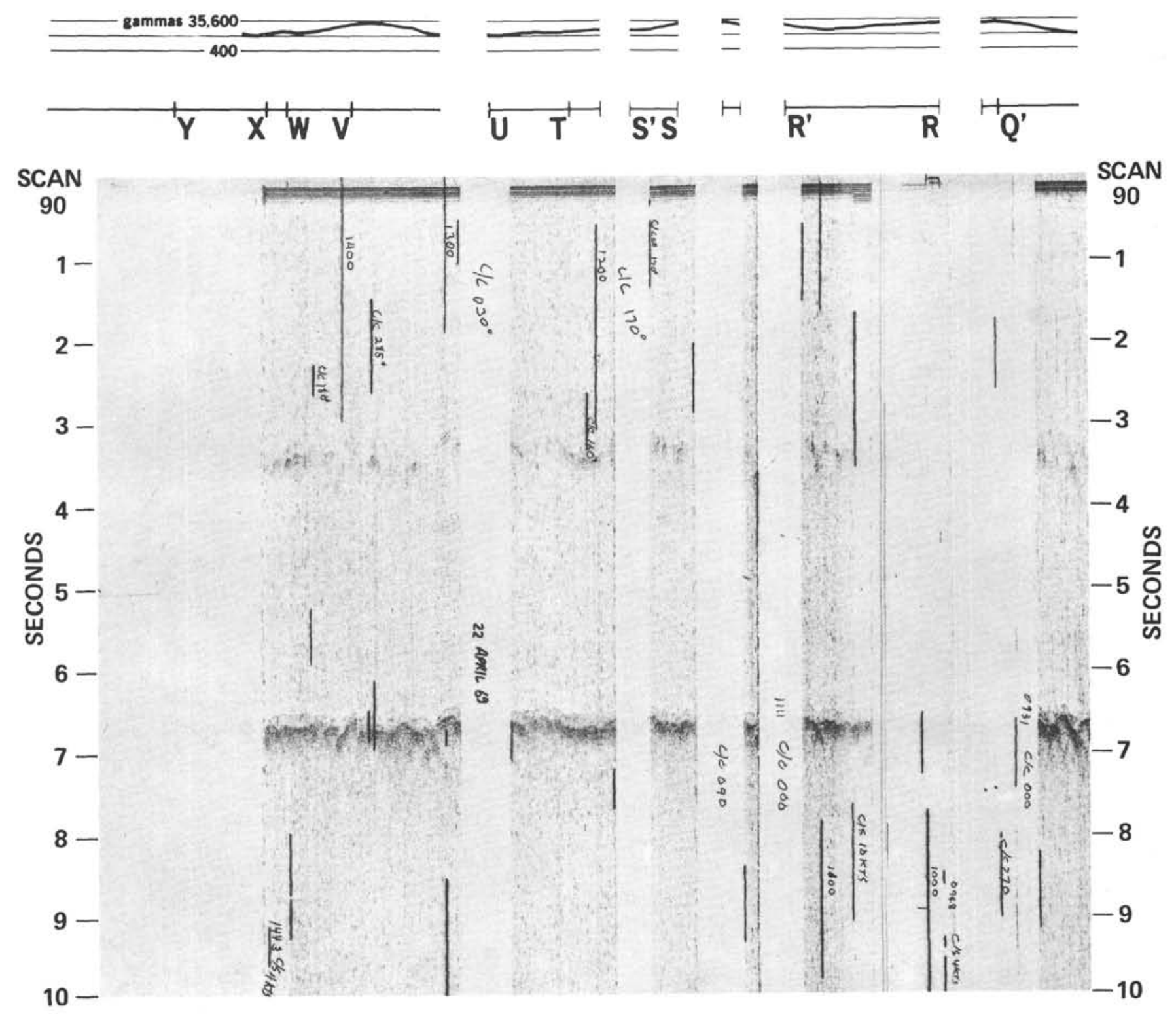

SCAN Survey, Site 10, Tracks $Q^{\prime}, R, R^{\prime}, S, S^{\prime}, T, U, V, W, X$ and $Y$. 


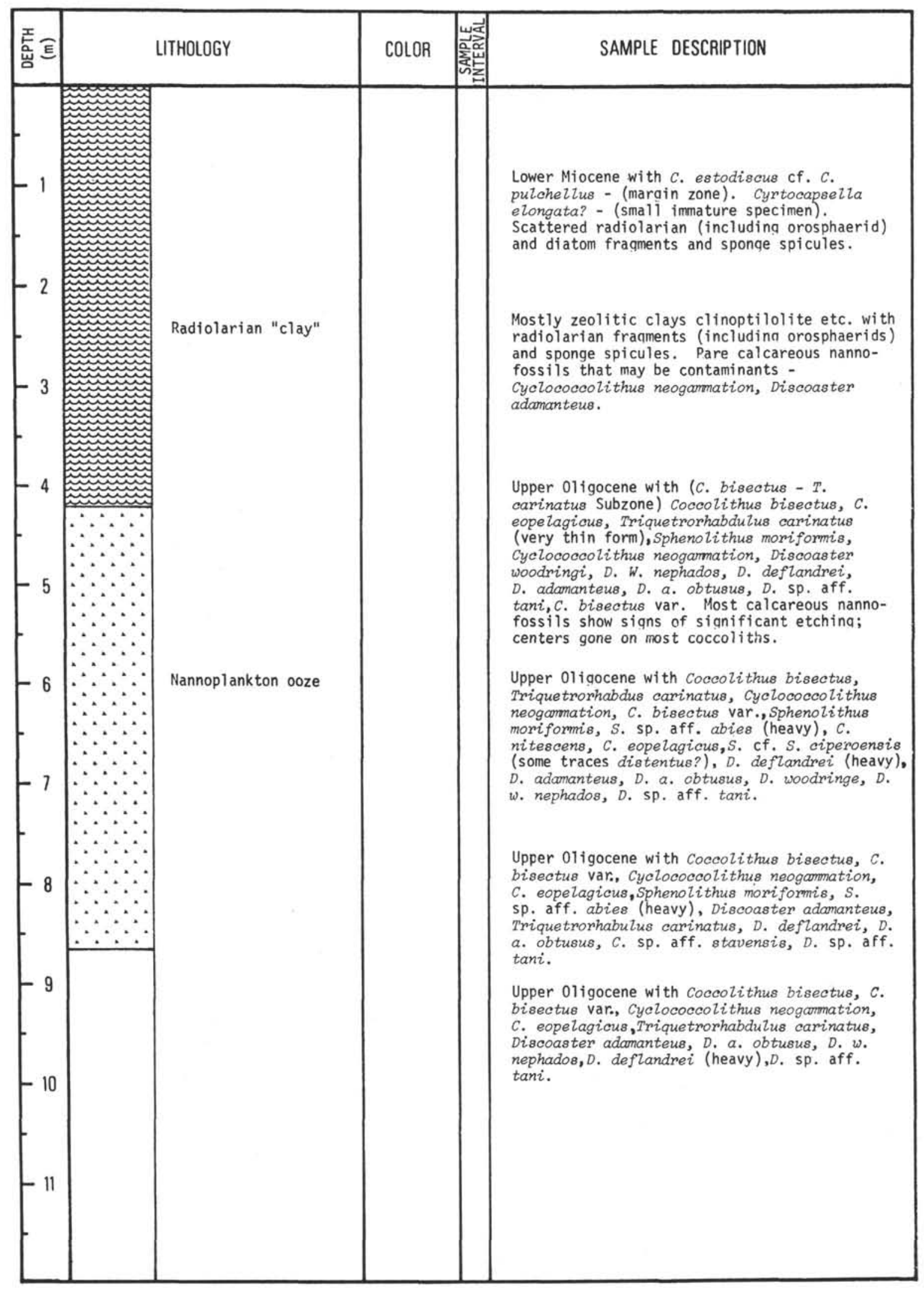

Summary of Piston Core 10. 